$\checkmark$ Research Square

\title{
Knowledge, Attitudes, Practices and Risk factors about Malaria in High Endemic Rural Eastern Tanzania
}

Ladslaus Laurent Mnyone ( $\square$ llaurent@sua.ac.tz)

Sokoine University of Agriculture, Pest Management Centre

\section{Baraka Mwamundela}

Sokoine University of Agriculture, Pest Management Centre

\section{Research Article}

Keywords: Malaria, Knowledge, Practices, Demographic risk factors, Eastern Tanzania

Posted Date: July 20th, 2020

DOI: https://doi.org/10.21203/rs.3.rs-41901/v1

License: (c) (1) This work is licensed under a Creative Commons Attribution 4.0 International License.

Read Full License 


\section{Abstract}

Background: Understanding area-specific knowledge, attitudes, practices and demographic risk factors towards malaria is becoming critical for designing appropriate awareness and control strategies.

Methods: A cohort of respondents from 243 randomly selected households across 3 villages in eastern Tanzania was assessed using a standard questionnaire and direct observation.

Results: Fifty-three percent of respondents cited Anopheles mosquitoes that were responsible for transmitting malaria, and $85 \%$ of those explicitly cited female Anopheles mosquitoes. The rest (47\%) knew that malaria is transmitted by a mosquito but could not name it. Commonly cited mosquito breeding sites were water bodies (75\%) and rubbish (24\%). Majority $(61 \%)$ knew that the under-fives were most vulnerable to malaria. ITNs were mostly $(64 \%)$ cited as a means of malaria control. Commonly cited malaria mosquito entry routes were windows (46\%), eave opening (10\%) and opening on the walls (4\%). Majority $(70 \%)$ confirmed malaria at the health facility. The rest $(30 \%)$ relied on symptoms. Majority (96\%) preferred modern antimalarials. Seventy-nine percent of the respondents owned at least one ITN. Cooking was done predominantly $(77 \%)$ outdoors, finished cooking and went to bed after 20:00h. Most $(58 \%)$ respondents still attended night-time outdoor communal gatherings without malaria protection.

Conclusions: The current study indicate that majority of participants were aware that Anopheles mosquitoes were responsible for transmitting malaria, they bred in water, under-five children were most vulnerable to malaria, and ITNs constituted the most deployed control measure. Most respondents preferred confirming malaria at the health facility and treatment with modern antimalarials. Yet, the rate of self-diagnosis and self-medication, as well as inappropriate use of bednets requires great improvement. Demographic risk factors for early-and/or outdoor-transmission included night-time outdoor cooking and attending communal gatherings without malaria protection. The findings warrant a subsequent study to show a causal link between night-time outdoor activities, vector biting patterns and malaria prevalence.

\section{Introduction}

Malaria remains a major cause of morbidity and mortality in tropical and subtropical regions of the world. In 2018, an estimated 228 million cases and 405 thousand deaths occurred worldwide. World Health Organization (WHO) African countries accounted for $93 \%$ of the cases and $94 \%$ of the deaths [1]. Tanzania is among the top ten countries with high malaria transmission and the population at risk in eastern and southern Africa [1, 2, 3]. Malaria is endemic in almost throughout the country, with over 95\% of the population at risk of infection. The disease causes approximately 7.7 million confirmed and clinical cases in the country annually $[2,4]$.

In Tanzania like other malaria-endemic countries, disease control efforts consist of timely diagnosis and treatment as well as the deployment of mosquito vector control interventions. The most frequently and widely used vector control interventions are long-lasting insecticidal nets (LLINS) and indoor residual 
spraying (IRS). LLINs and IRS in combination with timely diagnosis and appropriate treatment have halved malaria burden in the country [4]. Despite the progress made so far, the current control strategies in Tanzania and elsewhere in Africa are increasingly constrained by several challenges, the most important of which is the development of resistance to virtually all classes of insecticides used against malaria vectors [5-9]. Furthermore, the level of knowledge, attitudes and practices concerning the use of malaria control interventions varies greatly from one place to the other; and so is the disease prevalence. Several studies have shown that malaria vector distribution, transmission rates and incidence can vary widely over short distances, between neighboring villages and even within a single settlement, as a result of small area variations in risk factors [10-14]. As such, well-targeted efforts that embrace area-specific situations, at least in the remaining high malaria intensity foci, are needed to preserve the achieved health gains and advance towards elimination. Retrospective analysis of malaria cases in eastern Tanzania revealed two potentially high malaria endemic foci (Mkuyuni and Kiroka ward) in Morogoro Rural District, eastern Tanzania, with a prevalence of up to $61 \%$ [15]. Because of the aforesaid, this study assessed knowledge, attitudes, practices and demographic risk factors towards malaria amongst rural communities in a potentially high endemic area of eastern Tanzania to appropriately inform the future course of awareness campaigns, research as well as surveillance and control strategies.

\section{Materials And Methods}

\section{Description of the study area}

The study was conducted in Mkuyuni (latitude $6.57^{\circ}$ south and longitude $37.48^{\circ}$ east) and Kiroka (latitude $6.83^{\circ}$ south and longitude $37.78^{\circ}$ east) (Fig. 1). These wards are next to each other and are part of Morogoro Rural District, eastern Tanzania. Mkuyuni covers $97.4 \mathrm{~km}^{2}$ with a population of 17,935 people [16]. Kiroka covers $212 \mathrm{~km}^{2}$ with a population of 21,853 people [16]. Agriculture is the major economic activity across the two wards; and the main crops are rice, maize, banana, and coconuts. The long rain season runs from March to August and the short season runs from September to midDecember. The dry season runs from January to end of February. An estimated $96 \%$ of the houses in the area are made of mud-brick walls and iron roofs. The landscape is bestowed with temporal, semipermanent and permanent mosquito larval habitats, particularly in and around the agricultural fields. The population of malaria vectors largely composed of Anopheles gambiae sensu-lato and Anopheles funestus sensu-lato (Mnyone and Aikambe, Unpublished data). Malaria is experienced almost all year round with a peak in April and July [15].

\section{Data collection}

Simple random sampling technique was used to select study villages. The study households in each of the study villages were selected using a systematic random sampling technique. The relative contribution in terms of sample size was predetermined based on the size and number of households in the three study villages. A total of 243 households (Changa $=103$, Mkuyuni $=72$ and Mfumbwe $=68$ ) were finally 
selected and their respective heads or any other responsible adult interviewed after a brief, but thorough introduction to the study. A standardized questionnaire with structured and semi-structured questions was used as the main data collection tool. The questionnaire was written in English and translated into Kiswahili, a national language which was understood by all of the respondents in the study villages. The structured questionnaire and direct observations were done by a team of trained field workers and young graduates. The questions were mostly meant to seek information on, knowledge, attitudes and practices about malaria transmission, diagnosis, treatment and control. Also, there were questions meant to identify physical and socio-demographic features with potential for increasing the transmission risk of malaria in the study villages. Only one person per household was interviewed. The questionnaire was supplemented by direct observation to ascertain certain responses with immediate and/or readily available evidence including among other, ownership of bed net, other preventive measures, open eaves and other openings on the houses.

\section{Data analysis and presentation}

The collected data were summarized and analyzed by using Statistical Package for Social Sciences (SPSS) and Excel and presented in the form of tables. The collected data were computed in SPSS to obtain appropriate proportions and frequencies.

\section{Results}

\section{Socio-demographic characteristics}

A total of 243 respondents were interviewed during the period between February and April 2020 (Table 1). They comprised of males $(47 \%, 113 / 243)$ and females $(53 \%, 130 / 243)$ females. Most of them were over thirty years old $(167 \%, 162 / 243)$ and had primary education $(60 \%, 146 / 243)$. The next majority was below the primary level of education $(33 \%, 81 / 243)$. The most common occupation reported by respondents was crop farming $(87 \%, 211 / 243)$. Most of the study households had children below 5 years $(63 \%, 153 / 243)$ and/or $5-15$ years old $(74 \%, 181 / 243)$.

Table 1 Demographics of respondents and households from Changa, Mfumbwe and Mkuyuni village during the study period 


\begin{tabular}{|c|c|c|c|c|}
\hline \multirow[t]{2}{*}{ Category } & Changa & Mfumbwe & Mkuyuni & Total \\
\hline & $N=103 n(\%)$ & $N=68 n(\%)$ & $N=72 n(\%)$ & $N=243 n(\%)$ \\
\hline \multicolumn{5}{|c|}{ Age of the respondents (years) } \\
\hline $17-30$ & $35(34)$ & $17(25)$ & $29(40)$ & $81(33)$ \\
\hline $30+$ & $68(66)$ & $51(75)$ & $43(60)$ & $162(67)$ \\
\hline \multicolumn{5}{|c|}{ Sex of the respondents } \\
\hline Male & $44(43)$ & $38(56)$ & $31(43)$ & $113(47)$ \\
\hline Female & $59(57)$ & $30(44)$ & $41(57)$ & $130(53)$ \\
\hline \multicolumn{5}{|c|}{ Level of education of the respondents } \\
\hline Below primary & $43(42)$ & $20(29)$ & $18(25)$ & $81(33)$ \\
\hline Primary & $57(55)$ & $45(66)$ & $44(61)$ & $146(60)$ \\
\hline Above primary & $3(3)$ & $3(4)$ & $10(14)$ & $16(7)$ \\
\hline \multicolumn{5}{|c|}{ Occupation of the respondents } \\
\hline Farming & $95(92)$ & $64(94)$ & $52(72)$ & $211(87)$ \\
\hline Livestock keeping & $2(2)$ & $1(1)$ & $2(3)$ & $5(2)$ \\
\hline Employed & $4(4)$ & $1(1)$ & $2(3)$ & $7(3)$ \\
\hline Business & $2(2)$ & $2(3)$ & $16(22)$ & $20(8)$ \\
\hline \multicolumn{5}{|c|}{ Number of households with children } \\
\hline$<5$ years of age & $63(61)$ & $50(74)$ & $40(69)$ & $153(63)$ \\
\hline $5-15$ years of age & $73(71)$ & $57(84)$ & $51(71)$ & $181(74)$ \\
\hline
\end{tabular}

\section{Knowledge of malaria disease and interventions}

When asked about the vector of malaria, 53\% (129/243) of the respondents cited Anopheles mosquitoes. Eighty-five $(n=85)$ of those cited explicitly that it was female Anopheles mosquitoes. The rest of the respondents $(47 \%, 114 / 243)$ were aware that malaria is transmitted by mosquitoes but was not sure of the name of the mosquito. The most commonly reported mosquito breeding sites were water bodies $(75 \%, 182 / 243)$ and rubbish $(24 \%, 58)$. Interestingly, half of the respondents $(50 \%, 121 / 243)$ knew that they could still get malaria if bitten during the day (morning or late evening). Concerning the age group(s) at high risk of malaria, a significant proportion of respondents were able to cite the under-five children $(61 \%, 148 / 243)$. The rest of the respondents responded to either the adults $(6 \%, 15 / 243)$ or both the under-five children and adults $(30 \%, 74 / 243)$. When asked about the ways of controlling malaria, most 
respondents mentioned bed nets $(64 \%, 156 / 243)$. Other reported measures were cleaning surroundings $(19 \%, 47 / 243)$, spraying houses with chemicals $(1 \%, 3 / 243)$, and a combination of measures $(15 \%$, $37 / 243)$. Windows $(46 \%, 112 / 243)$ were the most commonly cited mosquito's entry route. Other reported routes were eave opening $(10 \%, 25 / 243)$ and opening on the walls $(4 \%, 9 / 243)$. The next majority $(37 \%$, $91 / 243)$ cited more than one mosquito entry route. Most respondents $(84 \%, 205 / 243)$ were aware that screening their windows would protect them from mosquitoes and malaria thereof. Furthermore, they affirmed that the risk of contracting malaria was much higher during the wet season. The results are summarized in Table 2.

\section{Attitudes towards malaria interventions}

When asked about the performance of bednets, $47 \%$ (113/243) of the respondents doubted that bednets can still reduce malaria. However, with an exception of $26 \%(29 / 113)$ of the respondents who said that mosquitoes can penetrate even intact nets, the rest $(64 \%, 84 / 113)$ were not sure of the reason(s). Interestingly, most respondents $(85 \%, 206 / 243)$ were aware and trusted that screening their windows reduces mosquitoes inside their houses and thereof malaria transmission.

Table 2 Respondent reported knowledge about malaria at Changa, Mfumbwe and Mkuyuni village during the study period 


\begin{tabular}{|c|c|c|c|c|}
\hline & $\begin{array}{l}\text { Changa } \\
\text { n (\%) }\end{array}$ & $\begin{array}{l}\text { Mfumbwe } \\
\mathrm{n}(\%)\end{array}$ & $\begin{array}{l}\text { Mkuyuni } \\
\text { n (\%) }\end{array}$ & $\begin{array}{l}\text { Total } \\
\text { n (\%) }\end{array}$ \\
\hline \multicolumn{5}{|c|}{ Do you know the type of mosquito that transmits malaria? } \\
\hline Anopheles & $18(17)$ & $14(21)$ & $13(18)$ & $45(18)$ \\
\hline Female Anopheles & $43(42)$ & $18(26)$ & $23(32)$ & $84(35)$ \\
\hline Not sure & $42(41)$ & $36(53)$ & $36(50)$ & $114(47)$ \\
\hline \multicolumn{5}{|c|}{ In which of these areas do mosquitoes breed? } \\
\hline Water bodies & $67(65)$ & $52(76)$ & $63(88)$ & $182(75)$ \\
\hline Rubbish & $33(32)$ & $16(24)$ & $9(12)$ & $58(24)$ \\
\hline Don't know & $3(3)$ & $0(0)$ & $0(0)$ & $3(1)$ \\
\hline \multicolumn{5}{|c|}{ Can you get malaria if bitten during the day? } \\
\hline Yes & $50(49)$ & $31(46)$ & $40(56)$ & $121(50)$ \\
\hline No & $35(34)$ & $37(54)$ & $32(44)$ & $104(43)$ \\
\hline Don't know & $18(17)$ & $0(0)$ & $0(0)$ & $18(7)$ \\
\hline \multicolumn{5}{|c|}{ Which of these groups have a high risk of getting malaria? } \\
\hline Children $<5$ years & $49(47)$ & $38(56)$ & $61(85)$ & $148(61)$ \\
\hline Adults & $9(9)$ & $5(7)$ & $1(1)$ & $15(6)$ \\
\hline Both groups & $45(44)$ & $19(28)$ & $10(14)$ & $74(30)$ \\
\hline Don't know & $0(0)$ & $6(9)$ & $0(0)$ & $6(3)$ \\
\hline \multicolumn{5}{|c|}{ Can you name ways for controlling malaria? } \\
\hline Use of Insecticide-treated Nets (ITNs) & $65(63)$ & $52(76)$ & $39(54)$ & $156(64)$ \\
\hline Cleaning surroundings & $23(22)$ & $15(22)$ & $9(13)$ & $47(19)$ \\
\hline Spraying chemicals & $1(1)$ & $1(2)$ & $1(1)$ & $3(1)$ \\
\hline Multiple ways & $14(14)$ & $0(0)$ & $23(32)$ & $37(15)$ \\
\hline \multicolumn{5}{|c|}{ Do you know the entry points of mosquitoes into the house? } \\
\hline Window openings & $45(44)$ & $37(55)$ & $30(42)$ & $112(46)$ \\
\hline Eave opening & $15(14)$ & $6(9)$ & $4(6)$ & $25(10)$ \\
\hline Wall openings & $3(3)$ & $3(4)$ & $3(4)$ & $9(4)$ \\
\hline Multiple points & $37(36)$ & $22(32)$ & $32(44)$ & 91 (37) \\
\hline
\end{tabular}




\begin{tabular}{|lrrrl|}
\hline Don't know & $3(3)$ & $0(0)$ & $3(4)$ & $6(3)$ \\
\hline Does screening of windows prevent malaria? & & & \\
\hline Yes & $81(79)$ & $62(91)$ & $62(86)$ & $205(84)$ \\
\hline No & $22(21)$ & $6(9)$ & $10(14)$ & $38(16)$ \\
\hline In which season of do we experience a high risk of malaria transmission? & \\
\hline Dry season & $10(10)$ & $18(27)$ & $4(6)$ & $32(13)$ \\
\hline Rain season & $91(88)$ & $47(69)$ & $63(87)$ & $201(83)$ \\
\hline Don't know & $2(2)$ & $3(4)$ & $5(7)$ & $10(4)$ \\
\hline
\end{tabular}

\section{Practices related to malaria disease and interventions}

Most of the respondents $(70 \%, 170 / 243)$ reported confirming whether they had malaria or not by presenting themselves to health facilities for diagnosis. The rest $(30 \%, 73 / 243)$ still relied on clinical symptoms. When asked whether they at times opted self-medication without a confirmatory diagnosis, $38 \%(92 / 243)$ of the respondents asserted to that. Interestingly, however, a vast majority $(96 \%, 233 / 243)$ preferred using modern remedies and extremely few $(4 \%, 10 / 243)$ still trusted herbal remedies. $18 \%$ $(43 / 243)$ of the respondents had lost family members in the past due to malaria and are therefore still concerned about the disease. Some respondents reported up to 5 deaths of their family members and/or close relatives in the past. Insecticide-treated nets (ITNs) remain the most predominantly used malaria control measure in the study area. When asked about malaria control measures, $91 \%(221 / 243)$ of the respondents cited bednets. Indeed, 79\% (192/243) owned at least one ITN and 76\% (184/243) claimed to have slept under an ITN the previous night. Other cited malaria control measures included cleaning surroundings $(6 \%, 14 / 243)$, spraying chemicals $(1 \%, 3 / 243)$ and other means $(2 \%, 5 / 243)$. The results are summarized in Table 3.

Table 3 Respondent reported practices related to malaria 


\begin{tabular}{|c|c|c|c|c|}
\hline & $\begin{array}{l}\text { Changa } \\
\text { n (\%) }\end{array}$ & $\begin{array}{l}\text { Mfumbwe } \\
\mathrm{n}(\%)\end{array}$ & $\begin{array}{l}\text { Mkuyuni } \\
\text { n (\%) }\end{array}$ & $\begin{array}{l}\text { Total } \\
\text { n (\%) }\end{array}$ \\
\hline \multicolumn{5}{|c|}{ How do you often confirm that you have malaria? } \\
\hline Disease symptoms & $35(24)$ & $15(22)$ & $23(32)$ & $73(30)$ \\
\hline Visit a health facility & $68(66)$ & $53(78)$ & $49(68)$ & $170(70)$ \\
\hline \multicolumn{5}{|c|}{ Do you sometimes use anti-malarial drugs without confirmation from a health facility } \\
\hline Yes & $44(43)$ & $24(35)$ & $24(33)$ & $92(38)$ \\
\hline No & $59(57)$ & $44(65)$ & $48(67)$ & $151(62)$ \\
\hline \multicolumn{5}{|c|}{ Do you sometimes treat malaria using traditional remedies? } \\
\hline Yes & $7(7)$ & $7(10)$ & $3(4)$ & $17(7)$ \\
\hline No & $96(93)$ & $61(90)$ & $69(96)$ & $226(93)$ \\
\hline \multicolumn{5}{|c|}{ Which local remedies do you often use to treat malaria? } \\
\hline Neem plant & $7(7)$ & $4(6)$ & $1(1)$ & $12(5)$ \\
\hline Lime fruits & $4(4)$ & $5(7)$ & $1(1)$ & $10(4)$ \\
\hline Others & $3(3)$ & $2(3)$ & $1(1)$ & $6(2)$ \\
\hline \multicolumn{5}{|c|}{ What do you prefer between modern and traditional remedies? } \\
\hline Modern remedies & $97(94)$ & $65(96)$ & $71(99)$ & $233(96)$ \\
\hline Traditional remedies & $6(6)$ & $3(4)$ & $1(1)$ & $10(4)$ \\
\hline \multicolumn{5}{|c|}{ Have you lost any family member(s) due to malaria? } \\
\hline Yes & $15(15)$ & $14(21)$ & $14(19)$ & $43(18)$ \\
\hline No & $86(83)$ & $54(79)$ & $58(81)$ & $198(81)$ \\
\hline Not sure & $2(2)$ & $0(0)$ & $0(0)$ & $2(1)$ \\
\hline \multicolumn{5}{|c|}{ How do you control malaria? } \\
\hline Use of ITNs & $94(91)$ & $64(94)$ & $63(87)$ & $221(91)$ \\
\hline Cleaning surroundings & $7(7)$ & $3(5)$ & $4(6)$ & $14(6)$ \\
\hline Spraying chemicals & $1(1)$ & $1(1)$ & $1(1)$ & $3(1)$ \\
\hline Other means & $1(1)$ & $0(0)$ & $4(6)$ & $5(2)$ \\
\hline \multicolumn{5}{|l|}{ Do you own a bednet(s) } \\
\hline Yes & $72(70)$ & $60(88)$ & $60(83)$ & $192(79)$ \\
\hline
\end{tabular}




\begin{tabular}{|lcccc|}
\hline No & $31(30)$ & $8(12)$ & $12(17)$ & $51(21)$ \\
\hline Did you sleep under an ITN last night? & & & \\
\hline Yes & $68(66)$ & $55(81)$ & $61(85)$ & $184(76)$ \\
\hline No & $35(34)$ & $13(19)$ & $11(15)$ & $59(24)$ \\
\hline Do you sometimes spray your houses with chemicals? & & \\
\hline Yes & $12(12)$ & $3(4)$ & $17(24)$ & $32(13)$ \\
\hline No & $91(88)$ & $65(96)$ & $55(76)$ & $211(87)$ \\
\hline How frequently do you spray? & & & $4(2)$ \\
\hline Every other day & $0(0)$ & $0(0)$ & $4(6)$ & $9(4)$ \\
\hline Every 3 months & $3(3)$ & $1(2)$ & $5(7)$ & $5(2)$ \\
\hline Every 6 months & $1(1)$ & $1(2)$ & $3(4)$ & $15(6)$ \\
\hline Variable & $8(8)$ & $2(3)$ & $5(7)$ & \\
\hline
\end{tabular}

\section{Demographic/household risk factors for malaria transmission}

The night-time cooking still took place predominantly outdoors $(77 \%, 187 / 243)$, more so during the dry season $(62 \%, 116 / 187)$. Most respondents $(54 \%, 101 / 187)$ reported finishing cooking normally on and after 20:00h. The rest $(47 \%, 88 / 187)$ normally finished cooking around 19:00h. Most respondents reported going to bed around $20: 00 \mathrm{~h}(40 \%, 97 / 243)$ and $\geq 21: 00 \mathrm{~h}(45 \%, 109 / 243)$. When asked about gatherings and/or ceremonies taking place outdoors during night-time, most respondents $(58 \%, 141 / 243)$ reported that they still take place and that people may spend more than three nights outdoors $(51 \%$, $121 / 243)$ oftentimes without any protection against malaria $(61 \%, 89 / 243)$. About $39 \%(55 / 243)$ claimed to protect themselves against malaria during those events, but they could not substantiate how they achieved that. The results are summarized in Table 4.

Table 4 Demographic/household outdoor malaria transmission risk features documented across study villages during the study period 


\begin{tabular}{|c|c|c|c|c|}
\hline & $\begin{array}{l}\text { Changa } \\
\text { n (\%) }\end{array}$ & $\begin{array}{l}\text { Mfumbwe } \\
\mathrm{n}(\%)\end{array}$ & $\begin{array}{l}\text { Mkuyuni } \\
\text { n (\%) }\end{array}$ & $\begin{array}{l}\text { Total } \\
\text { n (\%) }\end{array}$ \\
\hline \multicolumn{5}{|c|}{ Do you cook outside during night-time? } \\
\hline Yes & $78(76)$ & $51(75)$ & $58(81)$ & $187(77)$ \\
\hline No & $25(24)$ & $17(25)$ & $14(19)$ & $56(23)$ \\
\hline \multicolumn{5}{|c|}{ What time do you normally finish cooking? } \\
\hline Around 19:00h & $33(42)$ & $20(39)$ & $35(60)$ & $88(47)$ \\
\hline Around $20: 00 \mathrm{~h}$ & $5(7)$ & $12(24)$ & $11(19)$ & $28(15)$ \\
\hline$\geq 21: 00 h$ & $42(54)$ & $19(37)$ & $12(21)$ & $73(39)$ \\
\hline \multicolumn{5}{|c|}{ Do you also cook outside during wet season? } \\
\hline Yes & $37(47)$ & $26(51)$ & $8(14)$ & $71(38)$ \\
\hline No & $41(52)$ & $25(49)$ & $50(86)$ & $116(62)$ \\
\hline \multicolumn{5}{|c|}{ What time do you normally go to bed? } \\
\hline Around 19:00h & $12(12)$ & $10(15)$ & $15(21)$ & $37(15)$ \\
\hline Around 20:00h & $39(38)$ & $26(38)$ & $32(44)$ & $97(40)$ \\
\hline$\geq 21: 00 h$ & $52(50)$ & $32(47)$ & $25(35)$ & $109(45)$ \\
\hline \multicolumn{5}{|c|}{ Do you sometimes spend nights outdoors during ceremonies/events? } \\
\hline Yes & $56(54)$ & $43(63)$ & $42(58)$ & $141(58)$ \\
\hline No & $47(36)$ & $25(37)$ & $30(42)$ & $102(42)$ \\
\hline \multicolumn{5}{|c|}{ How many consecutive nights do people spend in one event? } \\
\hline 1 night & $35(34)$ & $26(38)$ & $15(21)$ & $76(31)$ \\
\hline 2 nights & $20(19)$ & $11(16)$ & $12(17)$ & $43(18)$ \\
\hline$\geq 3$ nights & $48(47)$ & $31(46)$ & $45(62)$ & $124(51)$ \\
\hline \multicolumn{5}{|c|}{ Do you use any protection against mosquitoes in such events? } \\
\hline Yes & $19(34)$ & $9(21)$ & $27(64)$ & $55(39)$ \\
\hline No & $37(66)$ & $34(79)$ & $15(36)$ & $86(61)$ \\
\hline
\end{tabular}

\section{Discussion}


Uptake and utilization of existing and novel malaria control interventions are often affected by knowledge, attitudes and practices amongst communities living in malaria-endemic settings. Similarly, documenting household demographic/household characteristics associated with increased mosquito biting risk is essential to inform the course of action in terms of designing behavioural change communication and other control interventions. This study assessed knowledge, attitudes, practices and demographic risk factors towards malaria amongst rural communities in a potentially high endemic area of eastern Tanzania. Findings from the study indicate an impressive level of knowledge on different aspects of malaria disease and control measures. More than $50 \%$ of the respondents knew that malaria is transmitted by Anopheles mosquitoes and that they breed in water bodies. However, rubbish was also reported by $24 \%$ of the respondents as a breeding site for Anopheles mosquitoes. Interestingly, up to half of the respondents were aware they could still get malaria if bitten before midnight including early morning and evening. Most communities in endemic areas believed malaria transmissions happen after midnight [17] most likely due to continued dissemination of outdated awareness messages [18]. Most messages date back to the 1990s and early 2000s when malaria mosquito bites were predominantly occurring indoors and late night-time. Despite the improvement in community awareness noted in this study, a considerable proportion of respondents as the case may be in other endemic areas, still rely on outdated messages. Not much advocacy, if at all, has been made to reflect the present situation on mosquito biting behaviours and malaria transmission [18]. Studies are increasingly documenting earlyand outdoor-biting in primary malaria vectors in Tanzania and elsewhere in Africa [19-22]. Therefore, the behavioural change communications need to be revised to reflect such changes to heighten awareness on the upcoming challenges in disease control. Otherwise, they will continue being inattentive to earlyand outdoor-malaria transmissions and thus constrain the global efforts to sustain the current health gains and advance towards elimination.

This study documented a considerable level of awareness among respondents concerning the age group most vulnerable to malaria and control measures. More than $60 \%$ of the respondents cited the under-five children as the most vulnerable group and ITNs as one of the most powerful control intervention currently available. Indeed, the under-five children across all endemic countries suffer the greatest malaria burden mostly due to lack of immunity to the disease [1, 23-24]. Similarly, ITNs remain the predominant control measure of choice across all malaria-endemic countries [1]. To enhance the impact of disease control efforts, the improved knowledge needs to be reflected on daily community practices. This is not fully realized in the present study areas as the case may be in other resource-poor malaria-endemic areas. Thus warranting continued behavioural change communications and improved access to control measures at local levels. The respondents recognized multiple entry routes for malaria mosquitoes however windows were by far the most commonly cited route. Extremely few respondents cited eaves although most of their houses had open eaves, and these have long been considered as the primary entry route into houses for malaria vectors [25-28]. This implies low awareness on the contribution of open eaves and therefore future awareness strategies should also emphasize the role of this entry route. These strategies will be enhanced by considerable improvement on literacy level and access to information in the study area and many other rural communities in Tanzania. We envision great improvement in malaria 
control if the advocacy is done alongside the improvement of housing styles happening in Tanzania and elsewhere in Africa. Interestingly, there are several on-going initiatives that emphasize on the house improvement as an alternative malaria control strategy. Expectedly, the benefits of such initiatives will soon be extended to Tanzania.

Most respondents (70\%) reported confirming malaria at the health facilities instead of self-diagnosis based on clinical presentations. Furthermore, $62 \%$ of the respondents reported that oftentimes they confirm the disease before taking antimalarial drugs obtained either from the health facilities or private drug dispensing shops. This complies with the government and WHO recommendation that all suspected cases should be confirmed either through microscopy or rapid diagnostic test before treatment [29]. A preference for testing before taking anti-malarial drugs has also been reported in other settings [30, 31]. The documented improvement in the study area may be explained by easy accessibility and quality of malaria diagnosis services provided by the resident health facilities and wide access to behavioural change communication (BCC) messages on malaria diagnosis through radios, televisions and health workers. Yet, self-diagnosis and medication remain a paramount concern in the study area $(\sim 30 \%)$ and elsewhere in Tanzania [32-35]. The most common reasons for these concerns include long distance to health facilities, inability to pay for healthcare charges, long waiting time at the health facilities, frequent shortages of medicines and poor attitudes on health workers [34, 35, 36-37]. We recommend a study to determine the contribution of these and/or other factors within the current study area. This will add great value to the current findings in favour of designing appropriate awareness and control strategies.

Up to $96 \%$ of the respondents, self- and health facility-diagnosed reported that they preferentially treat the disease using modern remedies. Only $4 \%$ of the respondents reported that they preferentially treat the disease using traditional remedies. This implies that reported self-medication is most likely done using modern antimalarials. As such, continued encouragement for health-facility based diagnosis must go hand-in-hand with improvement on self-medication particularly in areas without or with insufficient healthcare facilities. Banning self-medication may encourage people to practice it more in hiding and result to even more devastating consequences. The sought solutions should otherwise aim to provide the necessary knowledge and ensure that self-medication is well guided. This can be achieved among other ways by disseminating clear messages about malaria as part of health education, and formulation of realistic treatment policies [38]. Such messages should also seek to raise community awareness and knowledge on non-malarial fevers. If practiced appropriately, self-medication is recognized worldwide as a major contributor to most health care systems [39].

A vast majority of respondents recognized the importance of ITNs but noted that they were not perfect. This is substantiated by the fact that up to $79 \%$ of the respondents owned at-least one ITN. High ITN ownership despite the admiration that they were not perfect agrees with the findings of studies in other malaria endemic areas in Tanzania [17]. If appropriately and regularly used, ITNs remain reliable preventive measures against malaria [1, 40-42], therefore their deployment within and beyond the study area must be encouraged. All respondents admitted that they were still concerned with malaria, more so 
when considering deaths of their family members or close relatives in the past. Therefore, ITNs remain inevitable in preventing malaria resurgence and devastating morbidities and mortalities of the past.

The proportion of malaria mosquitoes biting people outdoors is increasing in most endemic countries within the African region [19-22]. Such exposures are greatest for rural and resource-poor communities due to extensive outdoor night-time social, cultural and economic activities $[18,43]$. This study documented demographic features of similar nature which potentially increase the malaria transmissions outdoors and/or early before going to bed. A vast majority of the respondents in this study were cooking outdoors between 18:00h and 22:00h. Also, majority, including those not cooking outdoors went to bed after 20:00h. Furthermore, most respondents reported night-time communal ceremonies/gatherings, which may take more than three days. Similar observations are increasingly documented in many other malaria endemic resource-poor settings $[17,43,44-46]$. Cooking and communal ceremonies/gatherings have been reported among the popular activities that kept people outdoors in many endemic areas of Africa notably Kilombero Valley, southern Tanzania [17, 44, 47], Unguja Island, Zanzibar [46], northern Ghana [43] and northern Botswana [48]. In the study area, like in several other malaria endemic settings in Tanzania $[17,44,46]$ and elsewhere in Africa $[43,45,48]$, respondents reported little or no protection at all during outdoor activities at or away from home. Purportedly, the study communities experience a high risk of malaria because the documented night-time outdoor activities take long periods which may coincide with vector's peak biting time. Studies have consistently reported early- and/or outdoor exposure between 18:00h and 22:00h [17].

\section{Conclusions}

Findings from the current study indicate that majority of participants were aware that Anopheles mosquitoes were responsible for transmitting malaria, they bred in water, under-five children were most vulnerable to malaria, and ITNs constitute the most powerful control measure. But, knowledge gaps requiring consideration when designing behavioural change communications were also identified. Concerning practices towards malaria disease and control interventions, we documented promising proportion in terms of respondents who confirmed the disease at the health facilities, preference to modern rather than herbal remedies, and bednet ownership. However, the rate of self-diagnosis, selfmedication, and appropriate use of bednets require great improvement. Concerning demographic risk factors for early- and/or outdoor-malaria transmission, the majority cooked outdoors, slept late, and participated in several days of night-time communal gatherings without any protection against the disease. The findings warrant subsequent study to show a causal link between night-time outdoor activities, vector biting patterns and malaria prevalence.

\section{Declarations}

\section{Acknowledgements}


The authors are grateful to the study communities for their support and cooperation, and early career researchers at the Pest Management Centre for administering the questionnaire.

\section{Author's contributions}

All authors contributed to data collection and analysis, drafting or revising the article, gave final approval of the version to be published, and agree to be accountable for all aspects of the work.

\section{Funding}

Not applicable

\section{Availability of data and materials}

The data can be made accessible upon reasonable request to the corresponding author.

\section{Ethics approval and consent to participate}

Ethical approval was granted by the Ethics Review Committee of Sokoine University of Agriculture (SUA), Morogoro, Tanzania. All heads or any other responsible adults in the study households gave verbal consent before they participated in this study.

\section{Competing interests}

The authors declare that they have no competing interests.

\section{Consent for publication}

Not applicable

\section{References}

1. World malaria report. Geneva: World Health Organization; 2019.

2. Haemoglobin concentrations for the diagnosis of anaemia and assessment of severity. Vitamin and mineral nutrition information system. Geneva: World Health Organization 2011.

3. Winskill P, Rowland M, Mtove G, Malima RC, Kirby MJ: Malaria risk factors in north-east Tanzania. Malar J. 2011;10:98. 
4. TDHS-MIS: Tanzania Demographic and Health Survey and Malaria Indicator Survey. Dar es Salaam, Tanzania and Rockville, Maryland, USA; 2016.

5. Ranson H, N'Guessan R, Lines J, Moiroux N, Nkuni Z, Corbel V. Pyrethroid resistance in African anopheline mosquitoes: What are the implications for malaria control? Trends Parasitol. 2011;27:9198.

6. Kabula B, Kisinza W, Tungu P, Ndege C, Batengana B, Kollo D, et al. Co-occurrence and distribution of East (L1014S) and West (L1014F) African knock-down resistance in Anopheles gambiae sensu lato population of Tanzania. Trop Med Int Health. 2014;19:1-11.

7. Matowo J, Kitau JA, Kabula B, Kavishe R, Oxborough RM, Kaaya R, et al. Dynamics of insecticide resistance and the frequency of kdr mutation in the primary malaria vector Anopheles arabiensis in rural villages of Lower Moshi, North Eastern Tanzania. J Parasitol Vector Biol. 2014;6:31-41.

8. Riveron JM, Tchouakui M, Mugenzi L, Menze BD, Chiang M, Wondji CS. Insecticide Resistance in Malaria Vectors: An Update at a Global Scale. IntechOpen 2017;150-175.

9. Matiya DJ, Philbert AB, Kidima W, Matowo JJ. Dynamics and monitoring of insecticide resistance in malaria vectors across mainland Tanzania from 1997 to 2017: a systematic review. Malar J. 2019;18:

10. Lindsay SW, Campbell H, Adiamah JH, Greenwood AM, Bangali JE, Greenwood BM. "Malaria in a peri-urban area of The Gambia," Ann Trop Med Parasitol. 1990;84:553-562.

11. Drakeley C, Schellenberg D, Kihonda J, et al. "An estimation of the entomological inoculation rate for Ifakara: a semi-urban area in a region of intense malaria transmission in Tanzania," Trop Med Int Health. 2003;8:767-774.

12. Diuk-Wasser MA, Touré MB, Dolo G, Bagayoko M, Sogoba N, Sissoko I, Traoré SF, et al. Effect of rice cultivation patterns on malaria vector abundance in rice-growing villages in Mali. Am J Trop Med Hyg. 2007;76:869-74.

13. Kibret S, Alemu Y, Boelee E, Tekie H, Alemu D, Petros B. The impact of a small-scale irrigation scheme on malaria transmission in Ziway area, Central Ethiopia. Trop Med Int Health. 2009;15:41-50.

14. Rumisha SF, Shayo EH, Mboera LEG. Spatio-temporal prevalence of malaria and anaemia concerning agroecosystems in Mvomero district, Tanzania. Malar J. 2019;18:228.

15. Aikambe JN, Mnyone LL. Retrospective analysis of malaria cases in a potentially high endemic area of Morogoro Rural district, eastern Tanzania. Res Rep Trop Med. 2020;11:37-44.

16. National Bureau of Statistics, Population Census of 2012, Tanzania, 2013.

17. Finda MF, Moshi IR, Monroe A, Limwagu AJ, Nyoni AP, Swai JK, et al. Linking human behaviours and malaria vector biting risk in south-eastern Tanzania. PLoS ONE. 2019;14(6): e0217414.

18. Moshi IR, Manderson L, Ngowo HS, et al. Outdoor malaria transmission risks and social life: a qualitative study in South-Eastern Tanzania. Malar J. 2018;17:

19. Govella NJ, Okumu FO, Killeen GF. Insecticide-treated nets can reduce malaria transmission by mosquitoes which feed outdoors. Am J Trop Med Hyg. 2010;82:415. 
20. Russell TL, Govella NJ, Azizi S, Drakeley CJ, Kachur SP, Killeen GF. Increased proportions of outdoor feeding among residual malaria vector populations following increased use of insecticide-treated nets in rural Tanzania. Malar J. 2011;10:80.

21. Sougoufara S, Diédhiou SM, Doucouré S, Diagne N, Sembène PM, Harry M, et al.Biting by Anopheles funestus in broad daylight after use of long-lasting insecticidal nets: A new challenge to malaria elimination. Malar J. 2014;13:125.

22. Cooke MK, Kahindi SC, Oriango RM, Owaga C, Ayoma E, Mabuka D, et al. A bite before bed': Exposure to malaria vectors outside the times of net use in the highlands of western Kenya. Malar $\mathrm{J}$. 2015;14:259.

23. Ong'echa JM, Keller CC, Were T. et al. Parasitemia, anemia, and malarial anemia in infants and young children in a rural holoendemic Plasmodium falciparum transmission area. Am J Trop Med Hyg. 2006;74(3):376-385.

24. van Eijk AM, Hill J, Noor AM, Snow RW, Kuil FO. Prevalence of malaria infection in pregnant women compared with children for tracking malaria transmission in sub-Saharan Africa: a systematic review and meta-analysis. Lancet Glob Health. 2015;3: e617-28.

25. Lindsay SW, Snow RW. The trouble with eaves; house entry by vectors of malaria. T Roy Soc Trop Med H. 1988;82(4):645-646.

26. Lindsay SW, Jawara M, Paine K, Pinder M, Walraven GE, Emerson PM. Changes in house design reduce exposure to malaria mosquitoes. Trop Med Int Health. 2003;8(6):512-517.

27. Njie M, Dilger E, Lindsay SW, Kirby MJ. Importance of eaves to house entry by anopheline, but not culicine, mosquitoes. J Med Entomol. 2009;46:505-10.

28. Kaindoa EW, Finda M, Kiplagat J, et al. Housing gaps, mosquitoes and public viewpoints: a mixed methods assessment of relationships between house characteristics, malaria vector biting risk and community perspectives in rural Tanzania. Malar J. 2018;17:

29. Guidelines for Treatment of Malaria. 2nd edition. Geneva, Switzerland: WHO; 2010.

30. Foster D, Vilendrer S. Two treatments, one disease: childhood malaria management in Tanga, Tanzania. Malar J. 2009;8:240.

31. Tarimo D, Lwihula G, Minjas J, Bygbjerg I. Mothers'perceptions and knowledge on childhood malaria in the holoendemic Kibaha district, Tanzania: implications for malaria control and the IMCl strategy. Trop Med Int Health. 2001;5:179-184.

32. Ruebush TK, Kern MK, Campbell CC, Oloo AJ. Self-treatment of malaria in a rural area of western Kenya. Bulletin of the World Health Organization, 1995;73(2):229-236.

33. Aborah S, Akweongo P, Adjuik M, Atinga RA, Welaga P, Adongo PB. The use of non-prescribed antimalarial drugs for the treatment of malaria in the Bolgatanga municipality, northern Ghana. Malar J. 2013;12:266.

34. Metta E, Haisma H, Kessy F, Hutter I, Bailey A. We have become doctors for ourselves: motives for malaria self-care among adults in southeastern Malar J. 2014;13:249. 
35. Babatunde OA, Fadare JO, Ojo OJ, Durowade KA, Atoyebi OA, Ajayi PO, Olaniyan T. Self-medication among health workers in a tertiary institution in South-West Nigeria. Pan Afr Med J. 2016; 24:312.

36. Bruxvoort K, Kalolella A, Nchimbi H, Festo C, Taylor M, Thomson R, et al. Getting antimalarials on target: impact of national roll-out of malaria rapid diagnostic tests on health facility treatment in three regions of Tanzania. Trop Med Int Health. 2013;18(10):1269-82.

37. Chipwaza B, Mugasa JP, Mayumana I, Amuri M, Makungu C, Gwakisa PS. Self-medication with antimalarials is a common practice in rural communities of Kilosa district in Tanzania despite the reported decline of malaria. Malar J. 2014;13:

38. Foster S. Treatment of malaria outside the formal health services. J Trop Med Hyg. 1995;98:29-34.

39. ???????

40. Okumu FO, Moore SJ. Combining indoor residual spraying and insecticide-treated nets for malaria control in Africa: a review of possible outcomes and an outline of suggestions for the future. Malar J. 2011;10:208 (2011).

41. Kilian A, Koenker H, Obi E, Selby RA, Fotheringham M, Lynch M. Field durability of the same type of long-lasting insecticidal net varies between regions in Nigeria due to differences in household behaviour and living conditions. Malar J. 2015;14:123.

42. Solomon T, Loha E, Deressa W, Balkew M, Gari T, Overgaard HJ, Lindtjørn B. Bed nets used to protect against malaria do not last long in a semi-arid area of Ethiopia: a cohort study. Malar J. 2018;17:

43. Monroe A, Asamoah O, Lam Y, Koenker H, Psychas P, Lynch M, et al. Outdoor-sleeping and other night-time activities in northern Ghana: implications for residual transmission and malaria prevention. Malar J. 2015;14:35.

44. Monroe A, Harvey SA, Lam Y, Muhangi D, Loll D, Kabali AT, et al. "People will say that I am proud": a qualitative study of barriers to bed net use away from home in four Ugandan districts. Malar J. 2014;13:82.

45. Monroe A, Mihayo K, Okumu F, et al. Human behaviour and residual malaria transmission in Zanzibar: findings from in-depth interviews and direct observation of community events. Malar J. 2019;18:

46. Dunn CE, Le Mare A, Makungu C. Malaria risk behaviours, socio-cultural practices and rural livelihoods in southern Tanzania: implications for bednet usage. Soc Sci Med. 2011;72:408-17.

47. Chirebvu E, Chimbari MJ, Ngwenya BN. Assessment of risk factors associated with malaria transmission in Tubu village, northern Botswana. Malar Res Treat. 2014;2014:403069.

\section{Figures}




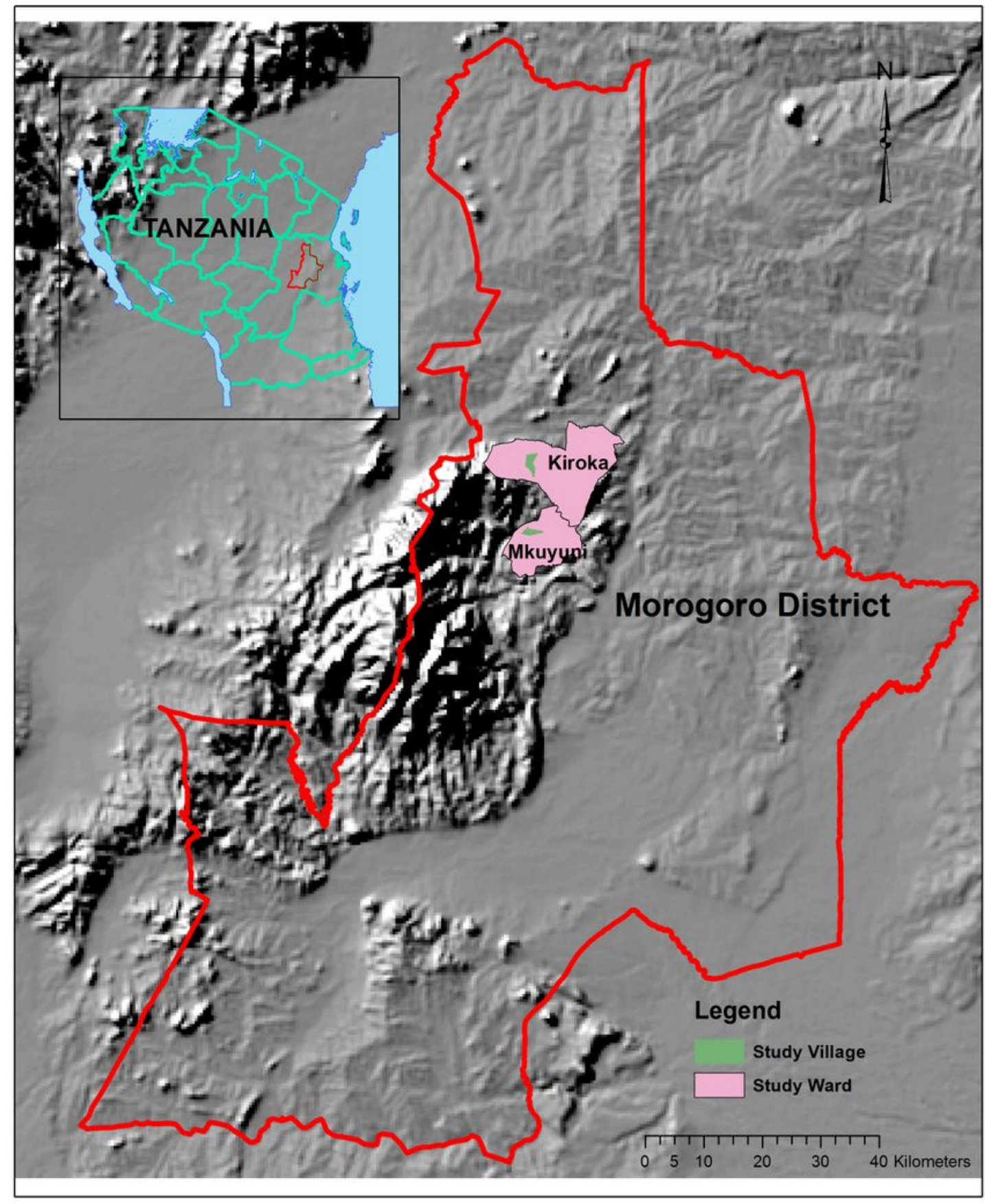

Figure 1

Map of the study area, Morogoro Rural District, Eastern Tanzania. 